\title{
A Study on the Value of New Generation Employee Help Scheme in Industrial Organization
}

\author{
GuangLi Luo
}

\begin{abstract}
Guangdong University of Foreign Studies South China Business College (School Code :12620), Guangzhou, guangdong, 510545 China

Corresponding author. Email: 2362404297@qq.com
\end{abstract}

\begin{abstract}
The employee help program of EAP (employee assistance program) is a practical and technical system of management psychology which studies the relationship management between the organization and the staff, explores the traditional interaction mode of changing the relationship between the organization and the staff, removes the unfavorable factors that affect the employee's work performance through professional methods, (and finally realizes the goal of harmony and win-win for the service content. The new generation employee help program) is a scientific intelligent management ecosystem based on EAP theory and technology. Through a comprehensive discussion on the background, theoretical exploration, function interpretation, model combing, practice summary and future trend analysis of the new generation employee help plan, the paper clarifies the positive effect of the new generation employee help plan on satisfying the organization and individual's establishment of living ecosystem in the present era. At the same time, it clarifies that the new generation employee help plan is a pioneering and innovative exploration of the theories and techniques of psychology and management, and provides a new way to promote the interdisciplinary integration of psychology, management and economics.
\end{abstract}

Keywords: EAP, new generation employee help plan, industry organization, organization ecology

\section{BACKGROUND}

With the rapid development of science, technology, information and economy in the world, the emergence of various industrial organization models, regional economic organizations, the increasing demands of cultural exchange among different organizations, the inherent value differences of various religious beliefs in the world, the conflicts caused by the uneven level of economic development in various regions, the increasingly complicated relationship between enterprises and employees or the endless internal disharmony caused by psychological factors fully reflect the new problems in the fields of management, cognition, human nature, communication, competition and so on in the present new demand for solving problems. The purpose of industrial organization economics is to solve the "Marshall conflict "[1]. All kinds of problems and conflicts in social relations can be summed up as interests and conflicts. Psychology studies human nerves, behavior, motivation, social relations, development and so on, giving psychology the value orientation of "eliminating the gap, coordinating the relationship, realizing the symbiosis and win-win of the related factors ". How to solve problems and coordinate conflicts through psychology is worthy of long-term exploration. To reconcile differences and resolve conflicts through psychological theory and technology is the research content of applied psychology and consulting psychology. Industrial organizations, as human social and economic organizations, involve communication and coordination such as "culture, management, relations, people and economic interests "; cross-regional and regional industrial organizations also involve the coordination and handling of religion, international security, international relations, social stability, etc. People, things and things that study industrial organizations have broad spectrum and representativeness. EAP (Employee Assistance Program) has great practical value in the fields of "social management[2], organizational management, humanistic management, communication management" and so on. But there are EAP technical limitations, (and the service area is relatively narrow. The new generation employee help plan) Technology is to carry on the expansion research to the EAP function with the help of the EAP value orientation, through the combination of multi-disciplinary theory[3], the technology participation, the information technology link, the practice verification and so on, uses the EAP idea connotation, the experience reference, with the information technology platform, uses the systematic thinking research and development utility model technology. The technology plays a role of harmonious management and value multiplication for industrial organizations, community organizations and even administration. 


\section{THE NEW GENERATION OF STAFF HELP PROGRAM}

A famous economist of the 20th century, a liberal thinker and industrial organization, Ludwig von Mises criticized "..... in his Preface on Epistemology of Economics study human behavior using newtonian physics to study mass and motion[3].To deal with people with the technology of engineers to deal with inanimate substances ", put forward the idea of opposing the materialization of people. "He is an individual, not a stone or atom that can be expressed precisely in numbers and that follows the rules of physics, "he said in Human Action. Miseus believes that economic science, as a science of human action, is completely different from the physical method of positivism. Miseus's research has opened up a wide field for applied research in the economic field of psychology, which is the same as the viewpoint of applied psychology that "all economic activities and relationships are the behavior responses of people under internal motivation [4]". He affirmed that man is conscious, that he has the mind, that the mind determines the goal of action, and that he perceives the conscious motive through introspection in addition to observing the person who is acting.

Mises laid the ideological foundation for a psychologybased new generation of employees to help plan economic research. Based on the EAP theory and technology, the new generation employee help plan is a scientific intelligent management ecosystem which combines information technology, artificial intelligence and highly humanistic care to establish ecological environment for the organization, to help the organization adapt to the complex business model of contemporary society, to meet the flexible and changeable management needs, and to help the organization establish a harmonious and symbiotic relationship with the staff. EAP employee help plan is to study the organization and employee relationship management, explore the traditional interactive mode of changing the relationship between the organization and the staff, eliminate the adverse factors that affect the employee's work performance through professional methods, and finally realize the management psychology practice technical system with the goal of harmonious winwin between the two sides as the service content.

The new generation employee help plan through the economic behavior and the behavior behind the motivation psychological cognition, the relationship coordination, the communication carries on the empirical research. The new generation of employee help program project team through the "economic behavior and psychological relevance scale" report showed: 2016 economic behavior and psychological relevance field survey, 1000 reported the correlation index 93\%. reveals any relationship between human behavior and psychology: except for stress events, human behavior is psychological explicit. Even what people often call "letting go" is a big reflection of the longstanding motivation for psychological preparation. This practice report provides the direction guide for the psychology and the new generation staff help plan to continue the thorough research, has opened up the broad anthropological exploration channel for the psychology. Traditionally, Marshall conflict is regarded as an economic conflict because of the contradiction between monopoly economy and market competition. The relationship between behavioral economy and psychological motivation analyzes Marshall conflict, and thinks that Marshall conflict is the conflict between people. In the eyes of philosophers, economics is the study of desire, and the problem of economics is the problem of psychology and work and values under human desire. Social and economic problems and conflict resolution are ultimately inseparable from the psychological communication under philosophy. As a result, the Marshall conflict remains a misallocation of resources due to lust. Under the condition of imbalance, the delisting behavior under the negative judgment of competitors eventually leads to the market losing its competitive vitality. MLM acts represent the imbalance of resource allocation caused by the imbalance of human desire on the other side of the Marshall conflict. Therefore, the economic crisis is still the product of behavioral economy and psychological motivation, and can still be recognized and improved through the study of the relationship between psychological motivation and behavioral economy[5].

Industrial economic theory is more based on the derivation of economic theory and model, ignoring the human factors, the motivation behind the behavior, the essence behind the phenomenon. Marx said that the outbreak of economic crisis will only occur in the capitalist economy, because they cannot overcome the contradiction between socialized mass production and capital privatization. Capitalists want to make more profits and expand the scale of production, while capital is not socialized to form a monopoly economy. On the one hand, social overproduction, on the other hand, because more people cannot afford goods, resulting in a serious imbalance in the allocation of social resources. This imbalance persists and eventually erupts in the form of an economic crisis at a point in time. Capitalists have always dominated the value of making more profits, but they also realize the potential role of charity in maintaining and increasing wealth. The charitable behavior of some capitalists for the purpose of maintaining and increasing wealth plays a certain role in healthy social and economic relations to a certain extent.

Take Alibaba's sharing economy as an example, each business environment of Alibaba embodies sharing. Sharing is charity in a broad sense, so human consciousness of sharing economy is to avoid the uncertainty and risk brought by economic crisis. Sharing economy can avoid economic conflict and economic crisis to some extent. And the capitalist's social responsibility consciousness is one of the ways to make the capital and social production obtain the benign allocation of resources, and finally solve all kinds of contradictions in the social economy. A certain number of state-owned enterprises and capitalists and entrepreneurs with social responsibility play a role in solving the rational allocation of social resources in a certain regional economy. Certain state-owned enterprises satisfy the condition of capital socialization: 
take it from civilian to civilian. And the capitalists and entrepreneurs with social responsibility effectively analyze social responsibility through self-psychological motivation and social psychological cognition, and then bear social responsibility. Taken together, it shows that human beings can avoid human economic conflict and other social conflicts through their own cognition of psychological motivation and behavior, and then improve the human economic environment and ecological economic model.

Using the theory of local psychology to analyze the natural and natural nature of Chinese Taoism is the most suitable rational allocation of resources, but it cannot find the theoretical basis to justify itself. The combination of psychology and economics makes the Tao method natural and natural to find a suitable point: when an economic decision is a moderate expression under our psychological motivation, it can drive people to achieve their own economic development, is positive; and when deviated from moderation, will present desire and plunder, leading to the imbalance of resource allocation under the motive impure. If the imbalance allocation continues to be enlarged to owners, companies, groups, industries will form a type of economic problems, showing economic research and problems to be solved. Therefore, the problem of economics lies in the imbalance of resource allocation, the essence lies in human nature and motivation, and in desire and psychology. Therefore, we can use psychological motivation to qualitatively explain the economic phenomena caused by good and bad behavior and motivation, and form a data model according to historical behavior data and psychological motivation statistics. The joint participation of economics and psychology can solve the social management of human nature to the good by data analysis. Psychology has long been waiting for the confusion of economics, so as to apply psychology to infiltrate it, for its prescription. The new generation of employee help programs is one of them. The new generation of employee help programs will play a unique role in solving economic problems.

\section{ANALYSIS ON THE VALUE OF NEW GENERATION EMPLOYEE HELP}

\section{PLAN3.1Technology roadmap}

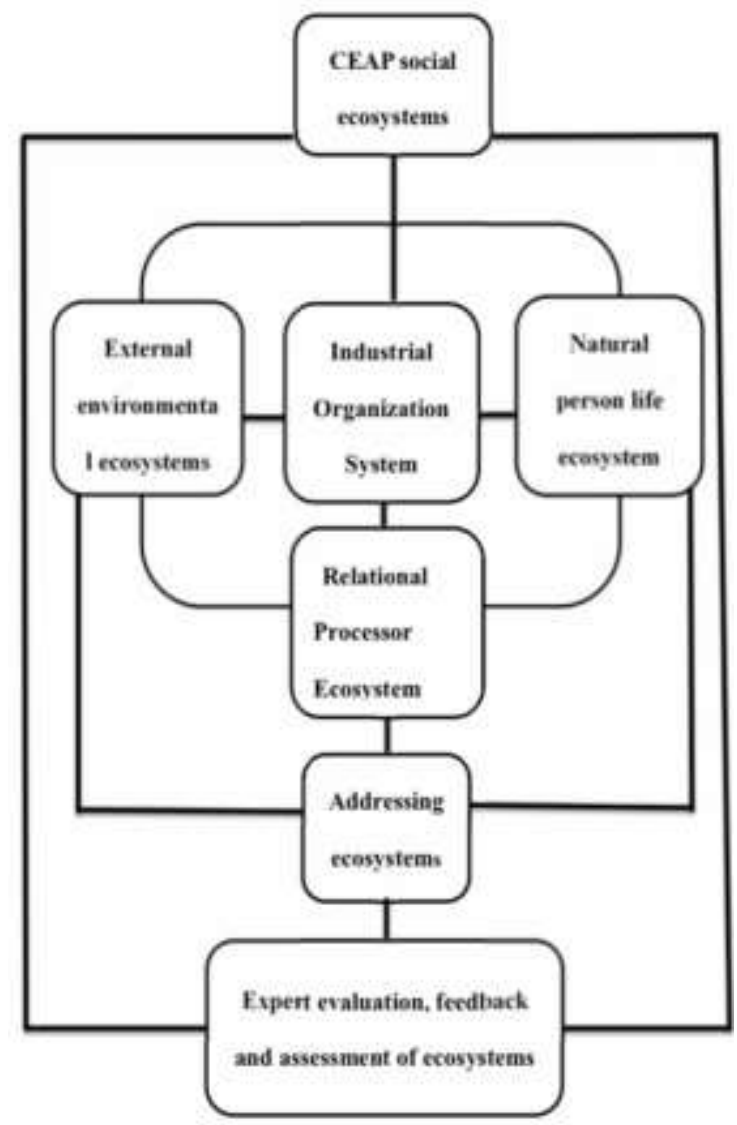

Figure 1 Technology roadmap 


\subsection{Value of the New Generation Staff Help Scheme in Industrial Organizations}

Conflict Management and New Generation Staff Help Scheme Value Link

(1) Micro-economic organizations will face the problems of strategy, human resources, finance, market and production, management, social organization coordination and so on. How to solve these problems, management has already carried out a variety of research, but finally, people-oriented management ideas to carry forward the future. Drucker, a master thinker in management, peter holiness, a human-oriented management mentor, and masno, a psychologist, are active in the world today. Organizational behavior and human resource management technology are the products of humanistic management thought. EAP enhance the humanistic care of human resource management and expand the field of service. EAP added human resources development, evaluation, teamwork, employee relationship management, career development, employee comprehensive help plan and so on. Organizational behavior practice also transition from production, management, management to learning organization, the fifth practice. The introduction of humanistic management thought makes the internal conflict of the long-standing mind factor organization resolved. As people understand that all resources in the organization take human resources as the first resource, the organization realizes the win-win relationship between the organization and the people through the encouragement and EAP of technical cooperation. The early theory that the relationship between organization and employee is judged to be contrary has become a history, and employees gain a sense of organizational belonging. Nowadays, the main contradiction of organization is from the problem of production management to the problem of "how to socialize the organization "and "organizational socialization thinking ". A kind of positive idea of rational allocation of organizational resources is coincidence and necessity. "How to Socialize Organizations" and "Social Thinking" are the answers to the Marshall conflict question. The resolution of the Marshall conflict ended with social thinking. The new generation of employee help programs is based on solving the problem of "how the organization is socialized" and "socialized thinking ". Psychological Analysis of Marshall Conflict in Industrial Organizations.

Industrial organization theory (Industrial Organization), to study the enterprise behavior and market structure of the market under the condition of incomplete competition, is mainly to solve the so-called "Marshall conflict" problem, that is, the conflict between the economies of scale effect of enterprises in the industry and the competitive vitality between enterprises. Mithos, a famous economist and thinker, said: "because man acts in this world with his free will, it is impossible for his actions to be summed up as quantitative historical laws."The further development of information technology presents a complicated economic model and interpersonal relationship, which makes industrial organizations have to face more complex internal and external relations and times problems than Marshall conflict. These problems can hardly be solved solely through economic means and management techniques. The new generation employee help plan has carried on the research exploration pertinently, seeks the effective solution, tries to use the psychology method to solve the economics question.

Mithos believes that human behavior has its particularity, so it is difficult to quantify and analyze the law of human action, so it is more important to grasp human behavior through perspective of human psychological motivation, and adopt strategies than direct analysis of behavior. Mises combines economics with sociology and human behavior, enriches and develops economics, and makes people see that the marshall conflict is a systematic conflict caused by the long-term accumulation of human desire and motivation, and finally evolves into a conflict of industry and the normal discussion under microeconomics. Alibaba uses the sharing economy form to allocate the resources reasonably, the economic model under the joint participation naturally dispels the social production surplus question and the competition question under the monopoly economy. Using psychology to recognize economic behavior motivation is far more effective than a mechanical derivation of an economic model, because all behavior arises from psychological motivation. People cannot let people stop desire, but through psychology to recognize desire, with the allocation of social resources to adjust desire, desire to satisfy the people and organizations are healthy and stable. Analyzing every business model of Alibaba, the communication mode between shop owner and buyer has extremely high psychological value factor. The essential cognition of psychology to business and organization management will be an indispensable research field in academic circles.

There are problems wherever there are people; the problems of any organization (except international events) are human problems. Industrial organization is the most essential special organization of interpersonal relations, there is a Marshall conflict that has long wanted to overcome, involving culture, management, relations, people and economic interests and other factors. More cross-regional industrial organizations also involve religion, international security, international relations, social stability, etc. It is of far-reaching significance to study the coordination of human, material and material relations of industrial organizations, harmony and winwin, organizational ecology and so on.

(2) Comprehensive Value of New Generation Employee Help Scheme in Industrial Organizations

Later Chinese social organizations have a large number of EAP project services. Some enterprises and working organizations have established EAP institutions or outsourced business to EAP professional organizations, so as to optimize the organization, help the organizational elements to grow actively, and finally help the organization to achieve strategic objectives. 
EAP benefits many organizations. An earlier study showed cost savings of $\$ 5$ to $\$ 16$ EAP an input. And more than a quarter of EAP benefits many organizations. An earlier study showed cost savings of \$enjoy EAP services all year round. More than 90per cent of the world's top 500companies have all established EAP organizations with more than EAP [5], people in the world,500 and more than 70per cent of 100-490companies have established EAP, and the number is increasing. EAP historical value is obvious to all. Science and technology information, economic globalization, digital rapid development, frequent cultural exchanges in the world, forming a variety of business models, economic organizations, cultural groups, communication channels, organizations and natural persons objective requirements must be socialized. The mode of economic, social and personal communication has reached a period of great transformation, and socialization is carried out passively without sufficient psychological preparation. The organization internal system, the natural person heart forms certain confusion and the panic. How to help organizations and natural persons to eliminate this fear and confusion caused by "unprepared ", EAP can not be solved, needs the new generation of employees to help plan the support of the intelligent system for the socialization of organizations and natural persons in the post EAP era.

Human beings constantly create problems in the process of solving problems, which is the result of desire and the source of economics. Social things need to be purified and refined to present in the world, good industrial organizations need to have good purification process support. The new generation employee help plan helps the industrial organization to construct the soul, forms the organization ecology, helps the industrial organization to realize the sustainable development healthily.

Take Alibaba and Apple as an example. Alibaba is known to have developed into an e-commerce kingdom in models and sales that are beyond popular imagination. The scale of cross-border has already realized the industrial "mass production ", and also realized the monopoly scale of ecommerce platform. From the successful case analysis of Alibaba e-commerce, we can see that Alibaba system and business model are social production and benefit sharing under cooperative mode. Alibaba's business philosophy, business model implementation, system platform service, after-sales service all present a healthy ecological view, forming their own e-commerce ecological industry chain. Apple also has its own humanistic feelings, with a super new generation of staff help planning system. Jobs's famous saying," living is to change the world," shows that he wants to use Apple's functions and systems to achieve his own humanistic feelings, but also wants to help more people to achieve the dream of changing their destiny. Apple is an ecological organization. Enterprises with ecological outlook will quickly complete the socialization process. Healthy socialized production must be socialized healthy organizational behavior, which can resolve economic conflicts and crises. Because Alibaba and Apple contain humanistic feelings and social responsibility in the cultural soil, they are enterprises with ecological genes.

(3) Product Service Model for New Generation Staff Help Scheme

At this stage, the new generation of staff help plan to APP point-to-point service, in the future will link more related servers, such as hospitals, information, business platforms, experts and so on, to create a social ecological environment to do the best service platform, purify society, promote civilization, achieve spiritual wealth harvest. At present, the advantage of APP function is to focus on specialized organizational consultation, personal consultation, organizational and personal relationship consultation, and to achieve 24-hour online service of expert network. Each solution is tailored and, at the same time, system data analysis is developed. As an organization, you can use the new generation of employees to help plan the wisdom system to understand the industry system big data information you want to know, business expansion services, solve your communication problems to customers, peers, industry systems, and achieve the established strategy of symbiosis and win-win[6].

\subsection{At this stage, the new generation of staff help plan model}

(1) Industry Chain +Model Industry chain +mode is to integrate the new generation employee help plan idea and technology mode into the industry chain, and gradually establish the industrial ecological environment through the operation activities. This mode has the most advantages, which can realize the healthy operation of each business activity under the support of ecological environment, strengthen the ecological environment in operation, and have a large advantage in late development, which can help to realize a more lasting and stable scale economy. And the shortcomings of economies of scale: long layout cycle, large investment of people and property, large workload of system maintenance, local problems spread quickly. Organizations suitable for this model include telecommunications, oil, industry alliance industries, education and health care.

(2) outsourcing service model Outsourcing service mode refers to outsourcing the new generation of employee help plan mode to professional service providers. can be local or the overall ecological environment layout outsourcing. Its advantages are: cost savings, flexible management. Disadvantages: poor system integration has a certain validity effect on the formation of self-ecological environment. It is suitable for mediu $\mathrm{m}$ and large organizations, developing organizations.

(3) Local Combination Patterns Alocal combination mode means that the industrial chain +mode is adopted in a certain industrial sector, and the industrial organization system is partially integrated. Its advantage is to save cost, have comparative advantage, can provide comparative parameters for more business behavior; the disadvantage is that there may be local imbalance phenomenon, which 
affects the objectivity of the overall data and the quality of the overall ecological environment. It is suitable for industry chain loose industry, or local improvement plan in the governance of the organization.

(4) problem-oriented model The problem-oriented model refers to the integration system of the new generation employee help planning model from the point of view of the problem. The firstthreemodels could be used. Its advantages are flexibility, cost saving and clear goal; the disadvantage is that it can not change the ecological environment of the organization in essence. It is suitable for temporary, shortand medium-term planning, industry turnover fast business, financial industry and so on.

\subsection{Comprehensive Analysis of the Value of the New Generation Staff Help Scheme}

(1) Feasibility Data Analysis of New Generation Employee Help Scheme Value

As the new generation of employee help program has not yet formed a perfect market system, so temporarily EAP data for industry analysis. The new generation employee help plan is based on the EAP development, uses the EAP data to do the reference analysis to have the extremely high appraisal validity. Conservative analysis EAP[7]: spending $\$ 1$ on a new generation of employee help programs can benefit five to eight times ecologically (not counting the future benefits of sustainable development). Professional analysis, Alibaba and Apple total revenue of more than half from the ecological concept of value gains. the regenerative value under ecological concept is greater. In the future, any business model formed from the concept of maintaining the health of the environment, society, organization and individual will form the core value and competitive advantage of the enterprise.

(2) new generation of staff to help plan other goals and values

The new generation of staff helps plan other goals and values reflected in the highly developed information technology of enterprises and social organizations socialization process, accelerate the pace of development of regional organizations and the world economic organizations, help to eliminate the long-standing conflicts in the economic field, as well as many conflicts in the management, communication problems, coordination of various forms of internal and external balance of industrial organizations, internal and external communication of social groups, accelerate the realization of specific economic organization goals. The new generation of employee help programs covering a variety of subject areas, such as economics, philosophy, psychology, biomedicine, physics, literature and art, information technology, artificial intelligence, brain science, ecommerce, etc., will help drive these subject areas. In the future, man-machine dialogue technology is a quantitative application of applied psychology. Help man-machine dialogue before, during and after the evaluation. The new generation employee help plan is widely involved in the human-computer dialogue specific technical support system and the ecological environment domain, manifests the new generation employee help plan unique value function. In the future, the new generation employee help program will serve the multi-domain with the role of social and industrial organization psychiatrist, realize the energy transformation between things in the organization, and help the organization become a healthy economic organization under mindfulness.

\section{CONCLUSIONS}

(1) The new generation of staff help program will be the process of human social, economic and cultural development for the coordination of contradictions, eliminate conflicts, establish relations, the realization of ideals will play a unique role in the development of human civilization.

(2) Organization's new generation employee help plan system will be the core competitiveness of the future enterprise.

(3) Due to the dynamic self-improvement characteristics of the new generation of employee help programs, the value and function are irreplaceable. Social and industrial organizations and individuals will apply and promote the new generation of staff help programs. The new generation employee help plan model will exist and develop for a long time with the development of human society civilization.

\section{ACKNOWLEDGMENT}

this paper is a school-level project "stress resistance research on healthy growth of college students (project number: 19-35B)", The Guangdong Professional Private Education Association 2019 research project "applied salaries in innovation and entrepreneurship research in private colleges and universities (project number :2019 GM 4.7).1), Guangdong University of Foreign Studies Nanguo Business School Management Institute Hetian Muxin Home won the fifth Guangdong Progressive External Standing Human Resources Award: mental health service key c Implementation project award new research results.

\section{REFERENCES}

[1] Xichao Zhang. The Theory and Practice of Staff Help Scheme Chinese EAP [M]. Beijing: China Social Sciences Press ,2010.] 
[2] Wu Jiawei. The Analysis of Network Economic Organization Theory Based on Network Externality - A New Idea Solve Marshall Conflict [J].] Modern Commerce and Industry ,2013,25(13):171-172.

[3] Dennis W.Carlton \&Jeffrey M.Pellov. Modern Industrial Organization [M]. Beijing: Renmin University Press, 2009.]

[4]Single Center Experience with Nivolumab Administration in NSCLC Patients from EAP Program [J]. Milos Pesek, Jana Durova, Gabriela Krakorova.P1.04-012 Journal of Thoracic Oncology, 2017, 12(1).

[5] Wu Shaofei, Lu Tao, Liu Jun, Yao Feng, Tang Jianqin. A Study on the Training Mode of Software Outsourcing Personnel [J].] Computer Products and Circulation, 2019(11): 233.

[6] Zhou Yangming. Deconstruction of Marshall Paradox Based on Dialectical Thinking [J].] Journal of Shanxi Normal University (Social Sciences Edition), 2018, 45(06):16-19.

[7]. "Marshall Conflict" and Effective Competition [J].] Journal of Shanghai Lixin Institute of Accounting, 2004(02):59. 